\title{
STRESS INTENSITY FACTOR SOLUTIONS FOR CRACKS IN THREADED FASTENERS
}

D. M. Oster and W. J. Mills

U. S. Department of Energy Contract DE-AC11-98PN38206

\section{RECEIVED \\ OCT 291999 \\ OSTI}

\section{NOTICE}

This report was prepared as an account of work sponsored by the United States Government. Neither the United States, nor the United States Department of Energy, nor any of their employees, nor any of their contractors, subcontractors, or their employees, makes any warranty, express or implied, or assumes any legal liability or responsibility for the accuracy, completeness or usefuiness of any information, apparatus, product or process disclosed, or represents that its use would not infringe privately owned rights. 


\section{DISCLAIMER}

Portions of this document may be illegible in electronic image products. Images are produced from the best available original document. 
TITLE OF SYMPOSIUM: "Second Symposium on Structural Integrity of Fasteners" STP $\underline{1391}$

AUTHORS' NAMES:

David M. Oster and William J. Mills

TITLE OF PAPER:

Stress Intensity Factor Solutions for Cracks in Threaded Fasteners

AUTHORS' AFFILIATIONS

Principal engineer and consultant, respectively, Bechtel Bettis Inc., Mail Stop 05KK, West

Mifflin, PA 15122 
ABSTRACT: Nondimensional stress intensity factor $(\mathrm{K})$ solutions for continuous circumferential cracks in threaded fasteners were calculated using finite element methods that determined the energy release rate during virtual crack extension. Assumed loading conditions included both remote tension and nut loading, whereby the effects of applying the load to the thread flank were considered. In addition, $\mathrm{K}$ solutions were developed for axisymmetric surface cracks in notched and smooth round bars. Results showed that the stress concentration of a thread causes a considerable increase in $\mathrm{K}$ for shallow cracks, but has much less effect for longer cracks. In the latter case, values of $\mathrm{K}$ can be accurately estimated from $\mathrm{K}$ solutions for axisymmetric cracks in smooth round bars. Nut loading increased $\mathrm{K}$ by about $50 \%$ for shallow cracks, but this effect became negligible at crack depth-to-minor diameter ratios $(a / d)$ greater than 0.2 . An evaluation of thread root acuity effects showed that root radius has no effect on $\mathrm{K}$ when the crack depth exceeds $2 \%$ of the minor diameter. Closed-form $\mathrm{K}$ solutions were developed for both remote-loading and nut-loading conditions and for a wide range of thread root radii. The $\mathrm{K}$ solutions obtained in this study were compared with available literature solutions for threaded fasteners as well as notched and smooth round bars.

KEYWORDS: threaded fasteners, stress intensity factor solutions, axisymmetric cracks, axisymmetric finite element analysis 


\title{
Nomenclature
}

\author{
$\mathrm{a}=$ crack depth, inch $(\mathrm{mm})^{(1)}$ \\ $\mathrm{a}^{\prime}=$ assumed crack depth in $\mathrm{K}$ estimation procedure, inch (mm) \\ $\Delta \mathrm{a}=$ increment of crack extension, inch $(\mathrm{mm})$ \\ $\mathrm{d}=$ minor diameter of thread or notch, inch (mm) \\ $\mathrm{D}=$ major diameter of thread or outer diameter of notched or smooth bar, inch $(\mathrm{mm})$ \\ $\mathrm{E}=$ elastic modulus, psi (MPa) \\ $\mathrm{F}=$ nondimensional stress intensity factor, $\mathrm{F}=\mathrm{K} /(\sigma \sqrt{ } \pi \mathrm{a})$ \\ $F_{p}=$ thread root radius correction factor \\ $\mathrm{G}=$ strain energy release rate, in- $\mathrm{lb} / \mathrm{in}^{2}\left(\mathrm{~kJ} / \mathrm{m}^{2}\right)$ \\ $\mathrm{K}=$ stress intensity factor, $\mathrm{psi} / \mathrm{in}(\mathrm{MPa} \sqrt{\mathrm{m}})$ \\ $\mathrm{K}_{\mathrm{t}}=$ stress concentration factor \\ $\mathcal{L}=$ length of thread engagement, inch (mm) \\ $\mathrm{P}=$ load, $\mathrm{lb}(\mathrm{kN})$ \\ $\mathrm{p}=$ pressure applied to thread flank, psi (MPa) \\ $\mathrm{q}-\mathrm{y}=$ regression constants \\ $\sigma=$ stress $\left[\sigma=\mathrm{P} /\left(\pi \mathrm{d}^{2} / 4\right)\right.$ for notched or threaded bar; $\sigma=\mathrm{P} /\left(\pi \mathrm{D}^{2} / 4\right)$ for smooth \\ bar], psi (MPa) \\ $v=$ Poisson's ratio \\ $\rho=$ thread root radius, inch $(\mathrm{mm})$
}

(1) Dimensions for the unified standard threads studied in this paper are defined in inches. To be consistent with these dimensions, English units are used as the primary measure. Where appropriate, the metric unit equivalent has been included in parentheses. 


\section{Introduction}

Threaded fasteners used in the assembly of structural components are often subjected to high loads that can cause cracking and fracture. Failure processes typically involve crack initiation at a thread root and propagation across the fastener by fatigue or stress corrosion cracking. Final separation occurs when a critical crack size, controlled by the material's toughness, is reached. Accurate stress intensity factor $(\mathrm{K})$ solutions are required to predict crack growth rates and fracture conditions under prototypic loading conditions.

The goal of this study is to calculate nondimensional $\mathrm{K}$ values for continuous circumferential cracks emanating from the thread root region of standard thread forms. This crack configuration is applicable to fasteners subjected to uniform membrane stresses, particularly when the material is susceptible to cracking such that multiple cracks initiate around the circumference. These multiple cracks ultimately link together to form a continuous circumferential crack.

In this study, finite element method (FEM) analyses were performed to develop nondimensional $\mathrm{K}$ solutions for standard coarse thread-forms. Assumed loading conditions include both remote tension and nut loading (see Figures 1 and 2), whereby the applied load was reacted at the thread flanks. The effects of thread root radius on $\mathrm{K}$ were also evaluated. In addition, $\mathrm{K}$ solutions were developed for continuous circumferential cracks emanating from single notches and smooth surfaces. The resulting $\mathrm{K}$ solutions were compared with available solutions for threaded fasteners, ${ }^{(1-7)}$ notched round bars ${ }^{(8)}$ and smooth bars. ${ }^{(8-10)}$ 


\section{Numerical Analysis Methods}

An FEM program ${ }^{(11)}$ was used to calculate $\mathrm{K}$ solutions for continuous cracks in threaded fasteners and notched bars. The program uses eight node isoparametric quadrilateral elements and a strain energy release rate $(G)$ method to calculate stress intensity factors. The method allows the stress intensity factors to be calculated as a function of crack depth for a given geometry with one computer run. Multiple runs with special crack tip elements being located at different crack depths are not necessary to obtain the stress intensity factor vs. crack depth relationship with this strain energy release method.

To calculate the stress intensity factors, the corner and midside nodes of a finite element along the specified crack path are released to simulate an increment of crack extension $(\Delta a)$, equal to the length of the side of the finite element. As nodes are released, nodal displacements and nodal forces along the path are computed. The strain energy released for each crack extension increment is then calculated using the nodal forces prior to the node release and the nodal displacements obtained as a result of the release. Repeated application of this algorithm yields $\mathrm{G}$ as a function of the crack depth " $\mathrm{a}$ ". The corresponding values of $\mathrm{K}$ are computed by the following equation:

$$
K=\sqrt{\frac{E G}{1-v^{2}}}
$$

where: $E$ = elastic modulus

$$
v=\text { Poisson's ratio. }
$$


Four sets of axisymmetric FEM models are developed. The first set represents a uniform cylinder with a continuous circumferential crack. The results from this analysis are compared to literature $\mathrm{K}$ solutions ${ }^{(8-10)}$ to verify the analysis method. The second set of models represents notched cylinders with axisymmetric cracks. The notch depths and radii are chosen to represent the standard UNC thread forms listed in Table 1. The notch models provide stress intensity factors for the thread geometry without the complications of multiple threads and thread flank loading.

The third set of models, shown in Figure 1, represents threaded studs subjected to remote tension. The stud has a reduced shank diameter and six threads are modeled. A uniform axial load is applied to the shank and the stud is fixed vertically at the bottom. The crack plane is located at the root of the second thread from the shank. The fourth set of models, see Figure 2, represents engaged fasteners. As shown in Table 1, the engaged length is approximately one thread diameter with five to nine engaged threads being modeled. An axial load is applied to the shank and the top surface of the nut is fixed vertically. The crack plane is located at the first engaged thread. One unengaged thread is located before and after the engaged threads. Figure 3 shows the mesh detail at the thread root. Approximately 7000 quadrilateral elements are in the model. A mesh refinement study showed no significant difference in the $\mathrm{K}$ values in using 10 to 30 elements at the thread root. The models used for this study had 20 elements at the cracked thread root. The overlapping stud and nut thread flank nodes were tied together to transmit the thread loads to the nut. This prevents any slippage along the thread flank surfaces. 
The axisymmetric models used in this study assume that threaded fasteners consist of a series of parallel notches, rather than a continuous helix. The effect of ignoring the helix shape on the Mode I stress intensity factor is judged to be small, particularly since the helix angles are small.

The results from all four FEM models have been normalized based on the crack depth as measured from the surface of the smooth bar or from the notch or thread root. The notch or thread depth has not been included in the normalization of the results.

\section{Results}

\section{Cracks in Smooth Round Bars}

The accuracy of the FEM analyses was verified by comparing calculated $\mathrm{K}$ solutions for smooth and notched round bars with literature solutions. ${ }^{(8-10)}$ The nondimensional $\mathrm{K}$ solution developed in this study for a continuous circumferential crack in a round bar loaded by a uniform far field stress is given by:

$$
\frac{K}{\sigma \sqrt{\pi a}}=-3.519+\frac{1.361}{\left(1-\frac{2 a}{D}\right)}+\frac{0.0533}{\left(1-\frac{2 a}{D}\right)^{2}}+10.23\left(1-\frac{2 a}{D}\right)-15.828\left(1-\frac{2 a}{D}\right)^{2}+12.81\left(1-\frac{2 a}{D}\right)^{3}-3.995\left(1-\frac{2 a}{D}\right)^{4}
$$

where $\mathrm{D}$ is the bar diameter and $\sigma$ is the applied stress. The resulting $\mathrm{K}$ values are in excellent agreement with those developed by Lefort ${ }^{(8)}$ and Tada, et al. ${ }^{(9)}$ at all a/D values and Harris $^{(10)}$ at $\mathrm{a} / \mathrm{D}$ values greater than 0.3 . When $\mathrm{a} / \mathrm{D}$ is less than 0.3 , the Harris solution yields $\mathrm{K}$ values that are low by about $4 \%$. Figure 4 compares the various $\mathrm{K}$ solutions for a continuous circumferential crack in a 1 -inch $(25.4 \mathrm{~mm})$ round bar subjected to a remote 
tensile stress of 10,000 psi (68.9 MPa). This geometry was selected for later comparisons with threaded fastener solutions.

\section{Cracks in Notched Round Bars}

Nondimensional $\mathrm{K}$ solutions for a continuous crack emanating from a single notch in a round bar are provided in Figure 5. The notch geometries are consistent with the size and shape of standard UNC thread geometries. The normalized $\mathrm{K}$ values are seen to be very high for shallow cracks due to stress concentration effects, drop off rapidly with increasing crack depth-to-minor diameter ratio (a/d), reach a minimum value at an a/d of about 0.1 and increase rapidly beyond an a/d of 0.2 because of the increase in net section stress as the uncracked ligament becomes very small. For a/d values less than $0.2, \mathrm{~K} / \sigma \sqrt{ } \pi \mathrm{a}$ values are dependent on notch geometry. Notches with the smallest and largest thread dimensions $(1 / 4-20$ UNC and 4-4 UNC) yield the highest and lowest values, respectively, whereas the other notches $(1 / 2-13$ UNC to $2-4.5$ UNC) yield intermediate results. The nondimensional $\mathrm{K}$ solutions for each of these data sets are given by the following:

$$
\frac{K}{\sigma \sqrt{\pi a}}=q+r e^{-s \frac{a}{d}}+t \frac{a}{d}+u\left(\frac{a^{2}}{d}\right)^{2}+v\left(\frac{a^{3}}{d}\right)^{3}+w\left(\frac{a^{4}}{d}\right)^{4}+x\left(\frac{a^{5}}{d}\right)^{5}+y\left(\frac{a^{6}}{d}\right)^{6}
$$

where: $\quad d=$ minor diameter of notch or thread

$$
\begin{aligned}
\sigma & =\text { stress acting on notch plane }\left[\sigma=\mathrm{P} /\left(\pi \mathrm{d}^{2} / 4\right)\right] \\
\mathrm{P} & =\text { applied load } \\
\mathrm{q}-\mathrm{y} & =\text { regression constants. }
\end{aligned}
$$


The regression constants for the notched geometries are given in Table 2.

Figure 6 compares $\mathrm{K} / \sigma \sqrt{ } \pi \mathrm{a}$ values obtained using Equation (3) and Lefort's solutions for a continuous circumferential crack emanating from a single notch with a 1-8 UNC thread geometry and a 0.012 inch $(0.305 \mathrm{~mm})$ root radius. The theoretical stress concentration factor $\left(\mathrm{K}_{\mathrm{t}}\right)$ for this geometry, which is needed to calculate $\mathrm{K}$ per the Lefort solution, was estimated to be $4.6^{(12)}$ It is seen that the nondimensional $\mathrm{K}$ solution given by Equation (3) is in excellent agreement with that developed by Lefort.

\section{Cracks in Threaded Fasteners}

Nondimensional $\mathrm{K}$ solutions for threaded fasteners with continuous cracks subjected to remote loading are provided in Figure 7. The general trends are seen to be similar to those described earlier for notched bars. Intermediate size fasteners, with thread sizes ranging from 1/2-13 UNC to 2-4.5 UNC, exhibit similar K solutions because their thread root geometries scale proportionally. As a result, a single $\mathrm{K}$ solution provides an adequate fit of the $\mathrm{K} / \sigma \sqrt{ } \pi \mathrm{a}$ values for these fasteners. When a/d is less than $0.06, \mathrm{~K} / \sigma \sqrt{ } \pi \mathrm{a}$ values for the $1 / 4-20 \mathrm{UNC}$ thread are slightly higher, so a separate $\mathrm{K}$ solution was developed for this thread geometry. Normalized K values for the 4-4 UNC fastener under remote loading tend to be slightly lower than those for the intermediate sized fasteners at a/d values less than 0.04 , so a separate solution was developed for this geometry.

Nondimensional $\mathrm{K}$ solutions for threaded fasteners subjected to nut loading, which are provided in Figure 8, show the same general trends as the remote-loaded notches and threads. 
The normalized $\mathrm{K}$ levels are seen to be independent of thread form at all a/d values.

Therefore, a single $K$ solution was used to fit $K / \sigma \sqrt{ } \pi$ a values for nut-loaded threads. Due to model size limitations in the FEM program, an FEM solution for the 4-4 UNC faster with nut loading could not be obtained.

The nondimensional $\mathrm{K}$ solutions for fasteners subjected to remote or nut loading have the same form as Equation 3, and the regression constants are given in Table 2. These solutions are valid for crack depths ranging from $0.3 \%$ to $40 \%$ of the minor diameter.

The comparison in Figure 9 of $\mathrm{K}$ solutions for remote-loaded and nut-loaded fasteners and remote-loaded notched bars shows some interesting trends. For a/d values greater than $0.25, \mathrm{~K}$ solutions are independent of thread and notch geometries and loading conditions, but differences in $\mathrm{K}$ solutions are apparent at shorter crack depths. In this regime, nondimensional $\mathrm{K}$ values for the remote-loaded threads are significantly lower than those for a single notch, and the minimum value occurs closer to the thread root. This is because the smaller diameter fastener shank and preceding thread shield the crack from the full stress concentration effect of a notch.

The influence of nut loading becomes significant when $\mathrm{a} / \mathrm{d}$ is less than 0.2 , and the magnitude of this effect is seen to increase with decreasing crack depth. At a/d values below 0.02 , nut loading increases $\mathrm{K}$ by about $50 \%$. It is interesting to note that $\mathrm{K}$ solutions for nutloaded threads and remote-loaded notched bars are similar. By coincidence, it appears that 
the increase in local stresses due to nut loading is comparable to the stress concentration effect of a single notch.

While Figure 9 shows that the nut loading effect is significant, it is much lower than that reported by Toribio, et al., ${ }^{(4,5)}$ who studied the influence of nut loading on threaded fasteners with surface cracks. They found that nut loading increases $\mathrm{K}$ by about $80 \%$ to $230 \%$ at a/d values between 0.1 and 0.2 . While crack geometry differences may partially account for the different observed trends, the biggest effect is believed to be the assumed loading conditions on the thread flanks. Toribio, et al. ${ }^{(4,5)}$ assumed a constant pressure (p) applied to the thread flank just below the crack and half of this value $(\mathrm{p} / 2)$ on the second thread flank. This results in the first thread flank carrying $67 \%$ of the total load. They noted that this loading condition was considered to be "conservative from the fracture mechanics viewpoint." Indeed, FEM results from the current study suggest that the assumed loading condition is overly conservative. It was determined from the present analysis of a 1-8UNC thread that the first two engaged thread flanks carry $28 \%$ and $19 \%$ of the total load, respectively. These loads are significantly less than those modeled by Toribio, et al..$^{(4,5)}$ Further indication of the conservatism introduced by Toribio, et al. ${ }^{(4,5)}$ is provided by consideration of the $\mathrm{K}$ values for various $\mathcal{L} / \mathrm{D}$ ratios. It was found that decreasing the length of engagement $(\mathcal{L})$ causes a modest increase in $\mathrm{K}$ when $\mathcal{L}$ is less than the major diameter (i.e., $\mathcal{L} / D<1$ ). For example, decreasing the number of engaged threads from eight to four for a $3 / 4-10$ UNC thread (i.e., decreasing $\mathcal{L} / \mathrm{D}$ from 1.01 to 0.51 ) causes a $15 \%$ increase in $\mathrm{K}$ for an a/D of 0.005 and an $8 \%$ increase for an a/D of 0.1 . With increasing crack depth, this effect diminishes and it becomes negligible for a/D values beyond 0.3 . The sensitivity study 
also showed that $\mathcal{L} / \mathrm{D}$ has little effect on $\mathrm{K}$ when the length of engagement is greater than the fastener diameter. For example, an $80 \%$ increase in $\mathcal{L} / \mathrm{D}$ from 1 to 1.8 causes less than a $1 \%$ decrease in $\mathrm{K}$ at an a/D of 0.005 and has a negligible effect for $\mathrm{a} / \mathrm{D}$ values greater than 0.1 . The trends noted above, namely the increase in $\mathrm{K}$ with decreasing length of engagement when $\mathcal{L} / \mathrm{D}$ is less than unity and the lack of a significant effect when $\mathcal{L} / \mathrm{D}$ exceeds unity, are consistent with good fastener practices where the engaged length should be approximately equal to the nominal thread size. Note that the nondimensional $\mathrm{K}$ solutions given in Table 2 for nut-loaded fasteners were generated for $\mathcal{L} / \mathrm{D} \approx 1$.

Based on these trends, it is concluded that differences in the assumed loading conditions are responsible for the different nut-loading effects reported herein and by Toribio, et al. ${ }^{(4,5)}$ The loading of just the first two threads adjacent to a crack $(\mathcal{L} / \mathrm{D} \approx 0.25)$ represents a very conservative stress state that results in overly conservative estimates of $\mathrm{K}$, as noted by Toribio. ${ }^{(4)}$ The present analysis is judged to be slightly conservative because local plasticity effects are expected to produce a more even stress distribution for the first few engaged threads, in comparison to the current linear-elastic analysis where the first engaged thread carries a higher percentage of the load.

\section{Comparison of $K$ Values for Threaded Fasteners and Smooth Bars}

Figure 4 shows that $\mathrm{K}$ solutions for continuous circumferential cracks in smooth cylindrical bars can be used to estimate $\mathrm{K}$ for threaded fasteners. This approximation method assumes the following: 
diameter of bar = major diameter of the thread assumed crack depth $=$ actual crack depth + thread depth $\left[a^{\prime}=a+(D-d) / 2\right]$ stress $=$ load in shank $\div$ area based on major diameter [i.e., $\left.\sigma=\mathrm{P} /\left(\pi \mathrm{D}^{2} / 4\right)\right]$.

These values are then substituted into any of the $\mathrm{K}$ solutions for an axisymmetric crack in a smooth cylindrical bar. Figure 4 compares the approximation method (solid and dotted lines) with the FEM calculated $\mathrm{K}$ values for a 1-8 UNC thread (open symbols) subjected to a load of 7854 pounds ( $34.9 \mathrm{kN}$ ). Considering the nut loading case (triangles), the actual $\mathrm{K}$ values for cracks with infinitesimal depth approach zero because the $\sqrt{ } \pi$ a term is dominant. As the actual crack depth is increased to 0.002 and 0.010 inch ( 0.05 and $0.25 \mathrm{~mm}), \mathrm{K}$ increases rapidly to 5000 and $7000 \mathrm{psi} /$ in $(5.5$ and $7.7 \mathrm{MPa} / \mathrm{m})$, respectively. These values are seen to straddle the estimated $\mathrm{K}$ values, corresponding to the solid and dotted lines. For crack depths between 0.010 and 0.1 inch $(0.25$ and $2.5 \mathrm{~mm})$, the simple estimation method underestimates the actual $\mathrm{K}$ values by only $10 \%$. For crack depths greater than 0.1 inch $(2.5 \mathrm{~mm})$ the estimation method accurately predicts $\mathrm{K}$. In terms of the actual crack depth-to-minor thread diameter ratio, the estimation procedure provides $\mathrm{K}$ values that are conservative for very shallow cracks $(\mathrm{a} / \mathrm{d}<0.02)$, nonconservative by about $10 \%$ for $\mathrm{a} / \mathrm{d}$ values between 0.02 and 0.15 , and very accurate for $\mathrm{a} / \mathrm{d}$ values greater than 0.15 .

The same general trends are observed for the remote-loading case (circles), but predictions are substantially more conservative for shallow cracks and remain conservative until a/d values exceed 0.15 . For a/d values greater than 0.15 , the estimation method accurately predicts $\mathrm{K}$. 


\section{Thread Root Radius Effects}

A sensitivity study of thread root radius $(\rho)$ effects on $K$ values was conducted for a 18 UNC threaded fastener subjected to nut loading and findings are plotted in Figure 10. Root radii ranged from 0.003 to 0.024 inch $(0.08$ to $0.6 \mathrm{~mm})$, with the nominal root radius assumed to be 0.012 inch $(0.3 \mathrm{~mm})$. The ratio of nondimensional $\mathrm{K}$ values for a specific root radius versus the nominal 0.012 -inch $(0.3 \mathrm{~mm})$ radius is plotted in Figure 10 as a function of normalized crack depth. Root radius has no effect at a/d values greater than 0.02 and very little effect at a/d values between 0.01 and 0.02 . This is consistent with Cipolla's findings, ${ }^{(1)}$ whereby root radius effects are nearly attenuated when a/d is greater than 0.015 .

Figure 10 shows that root radius effects for shallow cracks can be divided into five categories: very sharp $(\rho \approx 0.003$ inch or $0.08 \mathrm{~mm})$, sharp $(\rho \approx 0.006-0.009$ inch or $0.15-0.23$ $\mathrm{mm})$, nominal $(\rho \approx 0.012$ inch or $0.3 \mathrm{~mm})$, blunt $(\rho \approx 0.015-0.018$ inch or $0.38-0.46 \mathrm{~mm})$, and very blunt ( $\rho \approx 0.024$ inch or $0.6 \mathrm{~mm}$ ). For thread forms other than $1-8 \mathrm{UNC}$, the root radii associated with these categories are expected to scale proportionally with thread diameter.

The correction factor $\left(\mathrm{F}_{\rho}\right)$ for each root radius category is provided by an equation in terms of a/d (see Figure 10). Thus, values of $K$ for threaded fasteners with various root radii can be computed by the following equation:

$$
K=F_{p} F \sigma \sqrt{\pi a}
$$


where $\mathrm{F}$ is the nondimensional $\mathrm{K}$ solution $\left(\mathrm{K} / \sigma \sqrt{ } \mathrm{ra}\right.$ ) calculated from Equation 3. $\mathrm{F}_{\mathrm{\rho}}$ is equal to unity when $\mathrm{a} / \mathrm{d}$ is greater than 0.2 and for threads with a nominal root radius, regardless of a/d. For very shallow cracks emanating from thread roots with a non-nominal radius, $F_{\rho}$ can be calculated from the following equations:

$$
\begin{array}{ll}
\text { Very Sharp Root Radius: } & F_{\rho}=1+0.589 \mathrm{e}^{-377 \mathrm{a} / \mathrm{d}} \\
\text { Sharp Root Radius: } & \mathrm{F}_{\rho}=1+0.175 \mathrm{e}^{-248 \mathrm{a} / \mathrm{d}} \\
\text { Blunt Root Radius: } & \mathrm{F}_{\rho}=0.774+0.226\left(1-\mathrm{e}^{-312 \text { a/d }}\right) \\
\text { Fully Blunt Root Radius: } & \mathrm{F}_{\rho}=0.667+0.333\left(1-\mathrm{e}^{-219} \mathrm{a} / \mathrm{d}\right)
\end{array}
$$

\section{Comparison of $K$ Solutions for Threaded Fasteners with Literature Results}

Figure 11 compares the present nondimensional $\mathrm{K}$ solutions for a 1-8 UNC threaded fastener containing a continuous crack with literature solutions for fasteners containing continuous, elliptical and straight cracks. For a/d values less than 0.04 , all of the $\mathrm{K}$ solutions are in good agreement as the literature values are bounded by the nut-loading and remoteloading solutions generated herein. In this regime, the stress concentration effects of the threads overwhelm differences in net section stress associated with continuous versus straight or semi-elliptical surface cracks. The K solution developed by Popov and Ovchinnikov ${ }^{(t)}$ for a continuous crack $^{1}$ emanating from the first engaged thread agrees with the present nutloading solution for a similarly oriented crack.

Popov and Ovchinnikov ${ }^{(7)}$ use the term "circular crack," but it appears to be a continuous circumferential crack. They state that the geometry was modeled as a body of rotation, and the $\mathrm{K}$ solution used as the basis of their solution is for an axisymmetric crack in a round bar. 
When a/d is greater than $0.04, \mathrm{~K}$ values for continuous cracks are much greater than those for straight or semi-elliptical shaped cracks due to differences in net section stress as the noncracked ligament for a continuous crack quickly decreases with increasing crack depth. This is apparent in Figure 11 as the $\mathrm{K}$ solutions for the two types of cracks diverge with increasing crack depth. It is also seen that the $\mathrm{K}$ solutions developed by Cipolla ${ }^{(1)}$ for straight-fronted cracks and Toribio et al ${ }^{(3)}$ for semi-circular and semi-elliptical cracks and the composite solution developed by James and Mills ${ }^{(6)}$ are in good agreement.

\section{Conclusions}

1. Closed-form nondimensional $\mathrm{K}$ solutions were developed for continuous circumferential cracks in UNC threaded fasteners subjected to remote loading and nut loading. The K solutions are valid for a/d values ranging from 0.003 to 0.4 for both loading conditions.

2. An evaluation of thread root acuity effects showed that root radius has no effect on $K$ when the crack depth exceeds $2 \%$ of the minor diameter. A root radius correction factor was integrated into the closed-form solutions that enables $\mathrm{K}$ to be computed for a shallow crack emanating from a thread root with an arbitrary radius.

3. For continuous circumferential cracks, it was found that no significant differences exist between remote and nut loaded studs for a/d values larger than 0.25 . For smaller a/d values, the increase in stress at the thread root caused by the thread flank loading increases the $K$ values for the nut loaded case. At an a/d value of 0.05 , the nut loaded $\mathrm{K}$ values are $60 \%$ larger. 
4. Comparison of the $\mathrm{K}$ solutions for a round smooth bar with an effective crack depth that includes the thread depth with the FEM solution for a nut loaded thread, showed excellent agreement for a/d values larger than 0.15 . The round bar solution is nonconservative by about $10 \%$ for a/d values between 0.02 and 0.15 .

\section{Acknowledgment}

This work was performed under U. S. Department of Energy Contract DE-AC1198PN38206 with the Bettis Atomic Power Laboratory. 


\section{References}

[1] Cipolla, R. C., "Stress Intensity Factor Approximations for Cracks Located at The Thread Root Region of Fasteners," Structural Integrity of Fasteners, STP 1236, American Society for Testing and Materials, 1995, pp. 108-125.

[2] Cipolla, R. C., "Stress Intensity Factor Approximations for Semi-elliptical Cracks at the Thread Root of Fasteners," Improved Technology for Critical Bolting Applications, ASME MPC-Vol. 26, pp. 49-58.

[3] Toribio, J., Sanchez-Galvez, V., Astiz, M. A., and Campos, J. M., "Stress Intensity Factor Solutions for a Cracked Bolt Under Tension, Bending and Residual Stress Loading," Engineering Fracture Mechanics, Vol. 39, 1991, pp. 359-371.

[4] Toribio, J., Sanchez-Galvez, V., and Astiz, M.A., "Stress Intensification in Cracked Shank of Tightened Bolt," Theoretical and Applied Fracture Mechanics, Vol. 15, 1991, pp. 85-87.

[5] Toribio, J., "Stress Intensity Factor Solutions for a Cracked Bolt Loaded by a Nut," International Journal of Fracture, Vol. 53, 1992, pp. 367-385.

[6] James, L. A. and Mills, W. J., "Review and Synthesis of Stress Intensity Factor Solutions Applicable to Cracks in Bolts,' Engineering Fracture Mechanics, Vol. 30, 1988, pp. 641-654.

[7] Popov, A. A. and Ovchinnikov, A. V., "Stress Intensity Factors for Circular Cracks in Threaded Joints," Strength of Materials, Vol. 15, 1983, pp. 1586-1589.

[8] Lefort, P., "Stress Intensity Factors for a Circumferential Crack Emanating from a Notch in a Round Tensile Bar," Engineering Fracture Mechanics, Vol. 10, 1978, pp. 897-904.

[9] Tada, H. P., Paris, P. C., and Irwin, G. R., The Stress Analysis of Cracks Handbook, Del Research Corporation, St. Louis, MO, 1985.

[10] Harris, D. O., "Stress Intensity Factors for Hollow Circumferentially Notched Round Bars," Journal of Basic Engineering, Transactions of the ASME, Series D, Vol. 89, 1967, pp. 49-54.

[11] Friedman, E., "Curvature Effects in Thick Cylindrical Shells With Continuous Surface Cracks," Proceedings, Fifth International Conference on Pressure Vessel Technology Vol. II: Materials and Manufacturing, ASME, New York, 1984, pp. 761-776.

[12] Peterson, R. E., Stress Concentration Factors, Wiley and Sons, 1974. 
Figure Captions

FIG. 1 - Finite element model of stud subjected to remote tension. (a) Axisymmetric model of stud. (b) Enhanced detail in threaded region. (c) Crack depth measurement.

FIG. 2 - Finite element model of stud subjected to nut loading. (a) Axisymmetric model of stud and nut. (b) Enhanced detail of thread/nut engagement (all threads are not shown).

FIG. 3 - Mesh detail at thread root. (a) Mesh detail for one stud thread. (b) Enhanced view of thread root showing stud/nut engagement.

FIG. 4 - $\mathrm{K}$ as a function of crack depth for a continuous circumferential crack in a 1-inch $(25.4 \mathrm{~mm})$ diameter bar loaded to 7854 pounds $(34.9 \mathrm{kN})$, which corresponds to a remote stress of $10,000 \mathrm{psi}(68.9 \mathrm{MPa})$. Values of $\mathrm{K}$ calculated by Equation 2 (solid line) are compared with literature solutions (broken and dotted lines). ${ }^{(8-10)}$ Circles and triangles represent $\mathrm{K}$ values as a function of crack depth (top axis) for remote-loaded and nut-loaded 1-8 UNC fasteners loaded to 7854 pounds (34.9 $\mathrm{kN})$. $\mathrm{K}$ values for fasteners can be estimated from smooth bar solutions based on an assumed crack depth (a'--bottom axis) that is equal to the thread depth plus actual crack depth.

FIG. 5 - Nondimensional $\mathrm{K}$ solutions for a continuous circumferential crack in a notched round bar. Notch geometries are consistent with UNC thread forms. Correlation equations for $\mathrm{K} / \sigma \sqrt{ } \pi \mathrm{a}$ as a function of $\mathrm{a} / \mathrm{d}$, as represented by the three lines, are provided in Table 2.

FIG. 6 - Nondimensional $\mathrm{K}$ solutions for a continuous crack in a round bar containing a single notch with a 1-8 UNC design. FEM solution, per Equation 3, agrees very well with Lefort solution. ${ }^{(8)}$

FIG. 7 - Nondimensional $\mathrm{K}$ solutions for a continuous circumferential crack in a threaded fastener subjected to remote loading. Correlation equations for $\mathrm{K} / \sigma \sqrt{ } \pi \mathrm{a}$ as a function of $\mathrm{a} / \mathrm{d}$, as represented by the three lines, are provided in Table 2.

FIG. 8 - Nondimensional $\mathrm{K}$ solutions for a continuous circumferential crack in a threaded fastener subjected to nut loading. The correlation equation for $\mathrm{K} / \sigma \sqrt{ } \pi \mathrm{a}$ as a function of $\mathrm{a} / \mathrm{d}$, as represented by the line, is provided in Table 2 .

FIG. 9 - Comparison of nondimensional $\mathrm{K}$ solutions for a notched round bar under remote tension and threaded fasteners under remote tension and nut loading. Regression constants for each curve are provided in Table 2.

FIG. 10 - Root radius correction factors for a 1-8 UNC threaded fastener subjected to nut loading. 
FIG. 11 - Comparison of nondimensional $\mathrm{K}$ solutions developed by FEM analysis for fasteners subjected to nut loading and remote loading (solid curves) with literature solutions (broken curves). ${ }^{(1-3,6,7)}$ 
TABLE 1-- Thread dimensions used in finite element models. Dimensions are in inches (1 inch $=25.4 \mathrm{~mm}$ ).

\begin{tabular}{|c|c|c|c|c|c|c|}
\hline \multirow{2}{*}{$\begin{array}{c}\text { Thread } \\
\text { Size }\end{array}$} & \multicolumn{3}{|c|}{ External Thread } & \multicolumn{2}{|c|}{ Internal Thread } & \multirow{2}{*}{$\begin{array}{l}\text { Number of } \\
\text { Engaged } \\
\text { Threads } \\
\text { Modeled }\end{array}$} \\
\hline & $\begin{array}{c}\text { Major } \\
\text { Diameter }\end{array}$ & $\begin{array}{c}\text { Minor } \\
\text { Diameter }\end{array}$ & $\begin{array}{l}\text { Root } \\
\text { Radius }\end{array}$ & $\begin{array}{l}\text { Major } \\
\text { Diameter }\end{array}$ & $\begin{array}{c}\text { Nut } \\
\text { Outside } \\
\text { Diameter }\end{array}$ & \\
\hline 1/4-20UNC & 0.24485 & 0.17725 & 0.003 & 0.2500 & 0.4375 & 5 \\
\hline 1/2-13UNC & 0.49305 & 0.39138 & 0.006 & 0.5000 & 0.7500 & 7 \\
\hline 3/4-10UNC & 0.74175 & 0.61165 & 0.009 & 0.7500 & 1.1250 & 8 \\
\hline $1-8 \mathrm{UNC}$ & 0.99050 & 0.82915 & 0.012 & 1.0000 & 1.5000 & 8 \\
\hline $2-4.5 \mathrm{UNC}$ & 1.98610 & 1.69560 & 0.020 & 2.0000 & 3.0000 & 9 \\
\hline 4-4UNC & 3.98470 & 3.65604 & 0.022 & & $M$ & \\
\hline
\end{tabular}

Note: The thread major (and pitch) diameters used in the FEM models are the average of the maximum and minimum values listed in ASME B.1.1-1989. The root radii are based on measurements of a representative sample of fasteners. The minor diameters were calculated to provide a full root radii and to be tangent to the thread flanks. 
TABLE 2 -- Regression constants for nondimensional $\mathrm{K}$ solutions for continuous circumferential cracks in notched bars and UNC threaded fasteners.

\begin{tabular}{|c|c|c|c|c|c|c|c|c|c|}
\hline Thread Form & $\mathbf{q}$ & $\mathbf{r}$ & $\mathbf{s}$ & $\mathbf{t}$ & $\mathbf{u}$ & $\mathbf{v}$ & $\mathbf{w}$ & $\mathbf{x}$ & $\mathbf{y}$ \\
\hline \multicolumn{10}{|c|}{$\begin{array}{c}\text { NOTCH / Remote Loading } \\
\text { (Validity Range: } 0.005 \leq \mathrm{a} / \mathrm{d} \leq 0.4 \text { ) }\end{array}$} \\
\hline $1 / 4-20$ & 2.9724 & 2.3701 & 146.14 & -49.168 & 663.24 & -4756.3 & 19040.4 & -39186.6 & 32963.9 \\
\hline $1 / 2-13$ to $2-4.5$ & 2.6878 & 2.3931 & 156.61 & -43.165 & 598.38 & -4372.3 & 17803.4 & -37149.5 & 31623.6 \\
\hline $4-4$ & 2.2356 & 2.6467 & 199.32 & -32.956 & 483.94 & -3651.2 & 15267.7 & -32539.5 & 28264.2 \\
\hline \multicolumn{10}{|c|}{$\begin{array}{l}\text { THREADED FASTENER / Remote Loading } \\
\text { (Validity Range: } 0.003 \leq \mathrm{a} / \mathrm{d} \leq 0.4 \text { ) }\end{array}$} \\
\hline $3 / 4-20$ & 2.1209 & 1.6351 & 181.09 & -35.837 & 574.20 & -4517.7 & 19137.2 & -40763.3 & 34960.7 \\
\hline $1 / 2-13$ to $2-4.5$ & 1.7303 & 1.4640 & 198.17 & -24.232 & 435.79 & -3682.2 & 16443.7 & -36347.5 & 32073.7 \\
\hline $4-4$ & 1.4137 & 1.5347 & 299.43 & -12.082 & 253.55 & -2366.9 & 11529.0 & -27203.4 & 25391.2 \\
\hline \multicolumn{10}{|c|}{$\begin{array}{l}\text { THREADED FASTENER / Nut Loading } \\
\text { (Validity Range: } 0.003 \leq \mathrm{a} / \mathrm{d} \leq 0.4 \text { ) }\end{array}$} \\
\hline $1 / 4-20$ to $2-4.5$ & 3.0149 & 2.4902 & 166.26 & -51.624 & 722.92 & -5342.9 & 21757.0 & -45123.3 & 37900.2 \\
\hline
\end{tabular}

$$
\frac{K}{\sigma \sqrt{\pi a}}=q+r e^{-s \frac{a}{d}}+t \frac{a}{d}+u\left(\frac{a^{2}}{d}\right)^{2}+v\left(\frac{a}{d}\right)^{3}+w\left(\frac{a}{d}\right)^{4}+x\left(\frac{a^{5}}{d}\right)^{5}+y\left(\frac{a}{d}\right)^{6}
$$

where: $a=$ crack depth, measured from root of notch or thread

$\mathrm{d}=$ minor diameter of notch or thread 


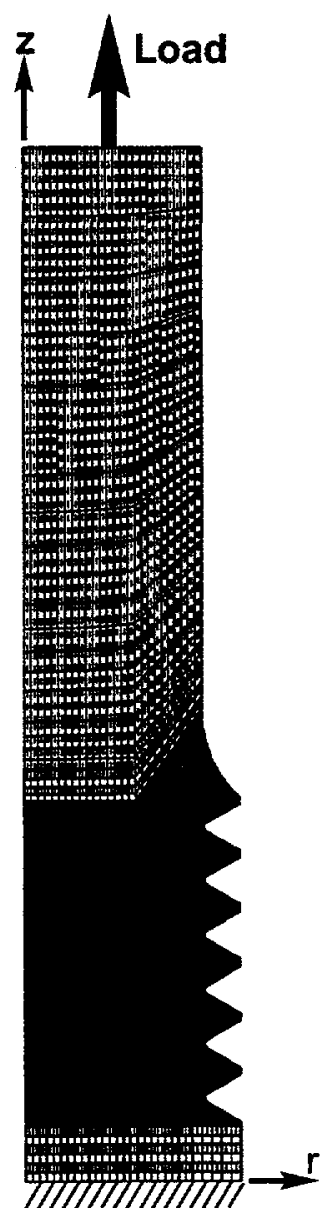

(a)

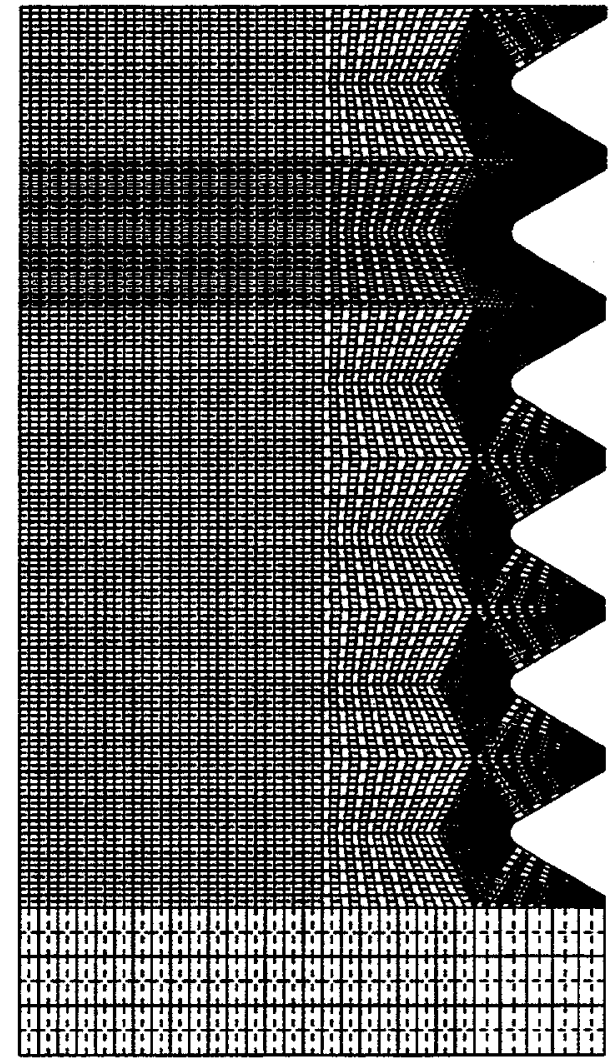

(b)

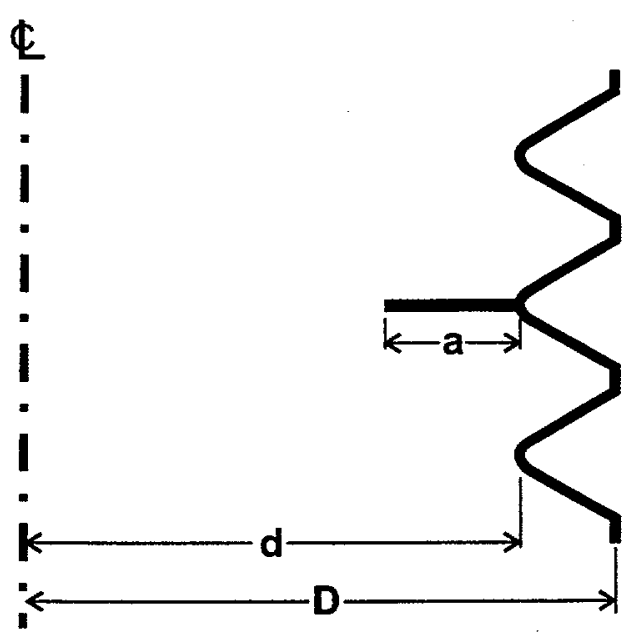

(c)

Figure 1 - Finite element model of stud subjected to remote tension. (a) Axisymmetric model of stud. (b) Enhanced detail in threaded region. (c) Crack depth measurement. 


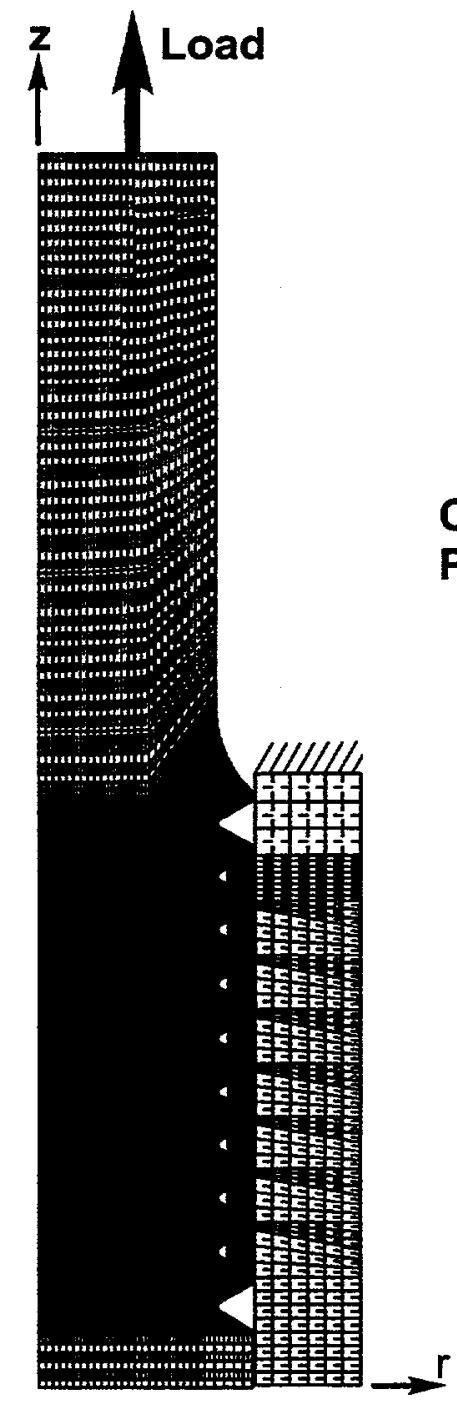

(a)

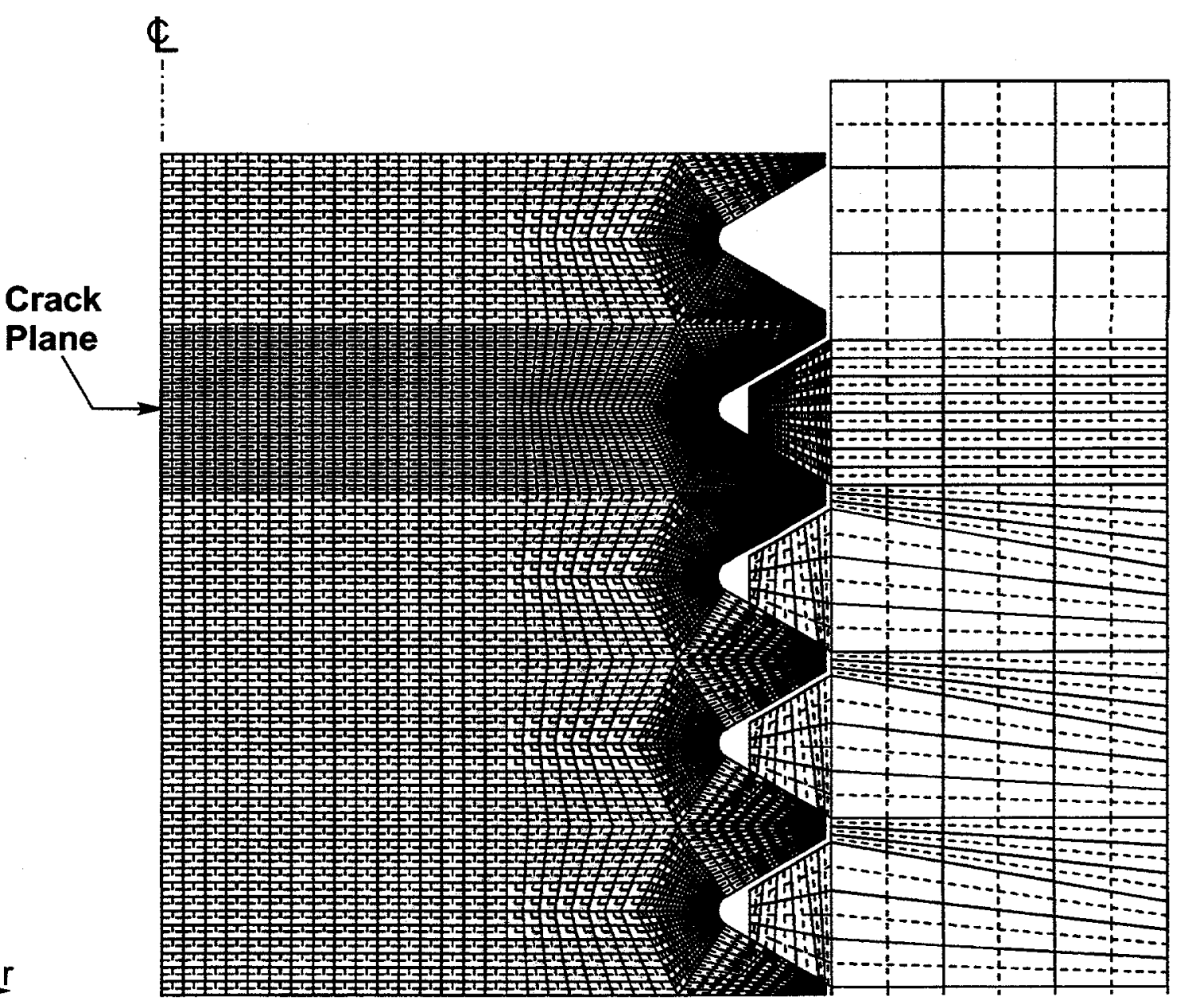

(b)

Figure 2 - Finite element model of stud subjected to nut loading. (a) Axisymmetric model of stud and nut. (b) Enhanced detail of thread/nut engagement (all threads are not shown). 


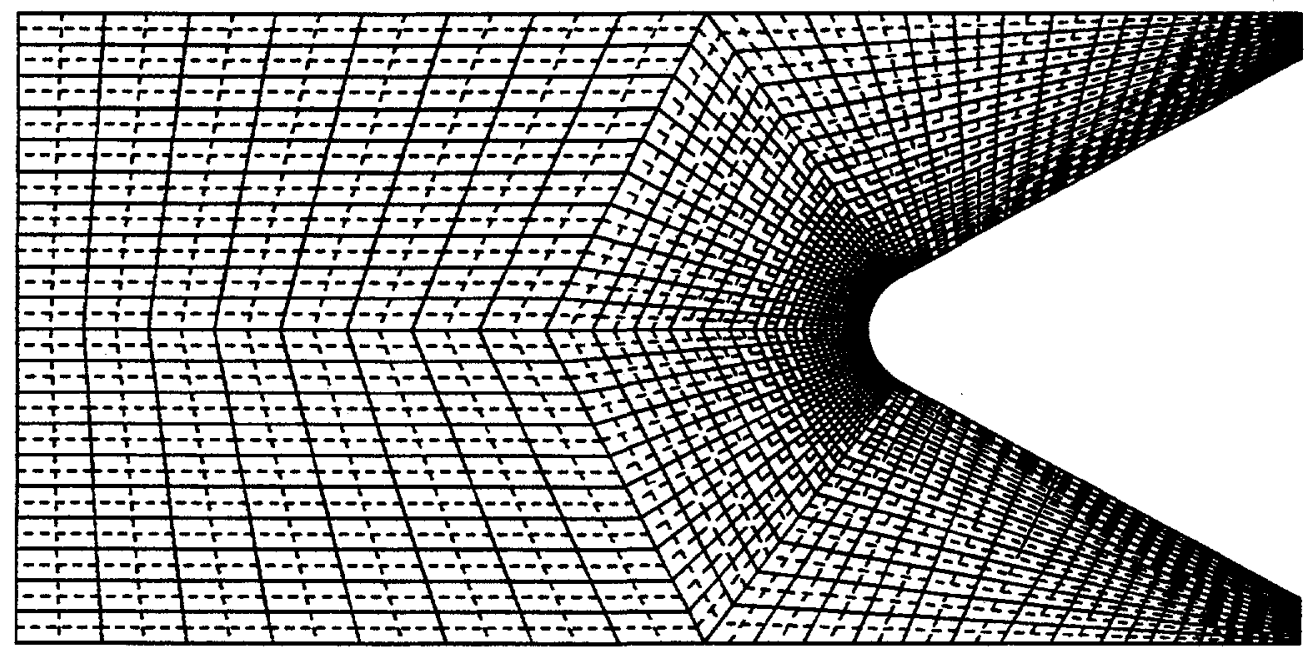

(a)

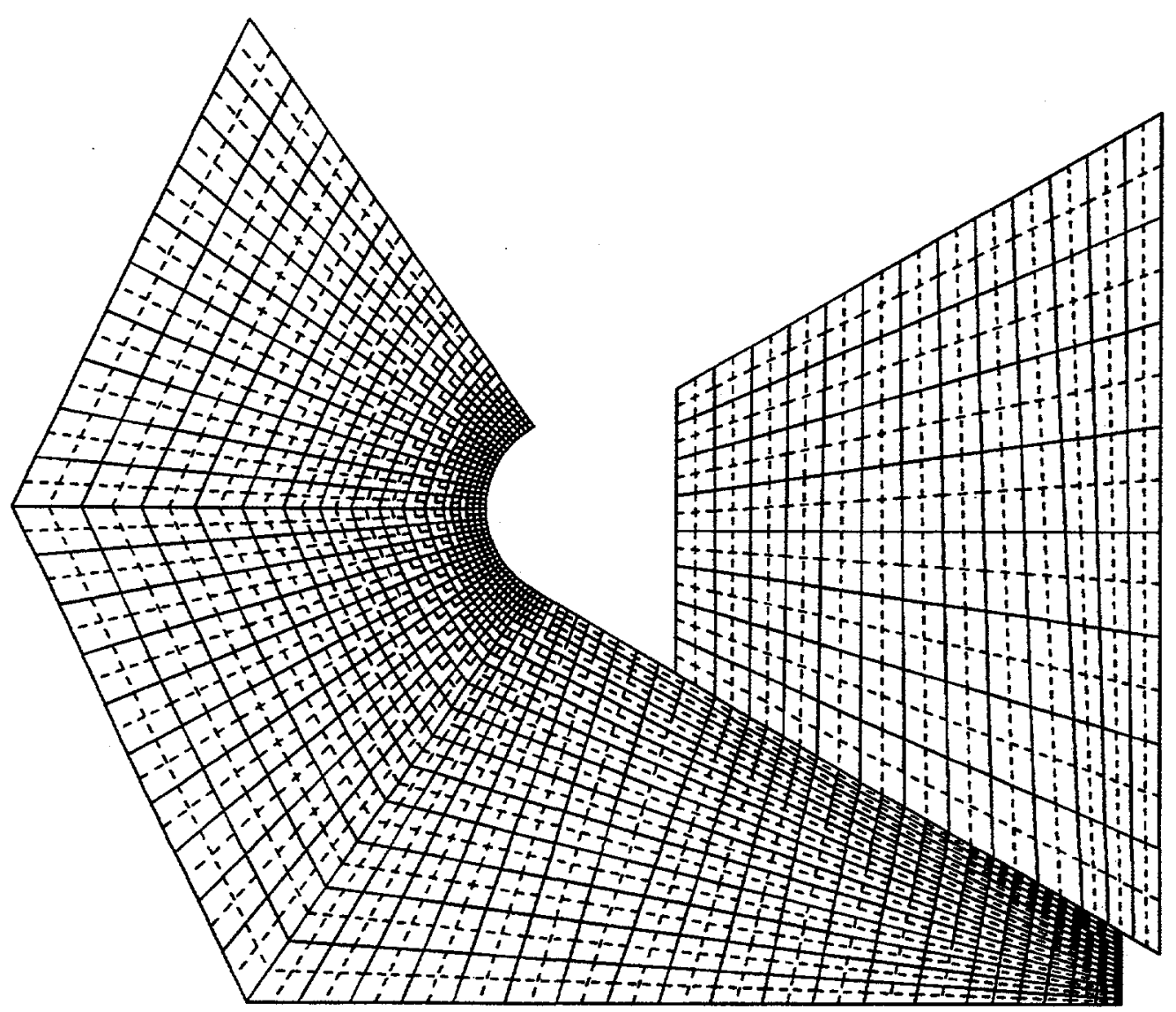

(b)

Figure 3 - Mesh detail at thread root. (a) Mesh detail for one stud thread. (b) Enhanced view of thread root showing stud/nut engagement. 
Crack Depth for Threaded Fastener, inch

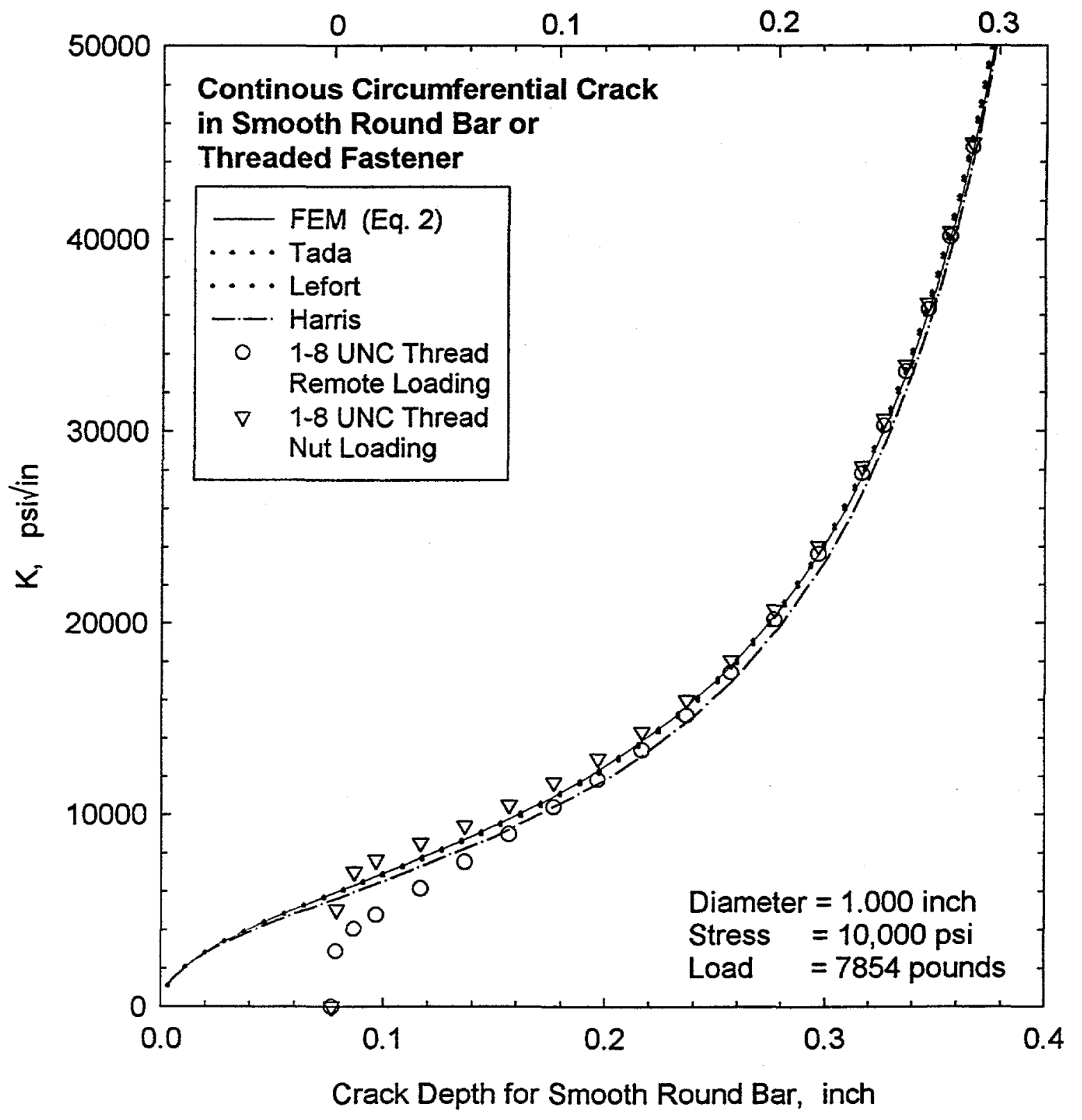

Figure 4 - $K$ as a function of crack depth for a continuous circumferential crack in a 1 -inch $(25.4 \mathrm{~mm})$ diameter bar loaded to 7854 pounds $(34.9 \mathrm{kN})$, which corresponds to a remote stress of $10,000 \mathrm{psi}(68.9 \mathrm{MPa})$. Values of $\mathrm{K}$ calculated by Equation 2 (solid line) are compared with literature solutions (broken and dotted lines). ${ }^{(8-10)}$ Circles and triangles represent $\mathrm{K}$ values as a function of crack depth (top axis) for remote-loaded and nut-loaded 1-8 UNC fasteners loaded to 7854 pounds (34.9 $\mathrm{kN})$. $\mathrm{K}$ values for fasteners can be estimated from smooth bar solutions based on an assumed crack depth ( $a^{\prime}-$-bottom axis) that is equal to the thread depth plus actual crack depth. 


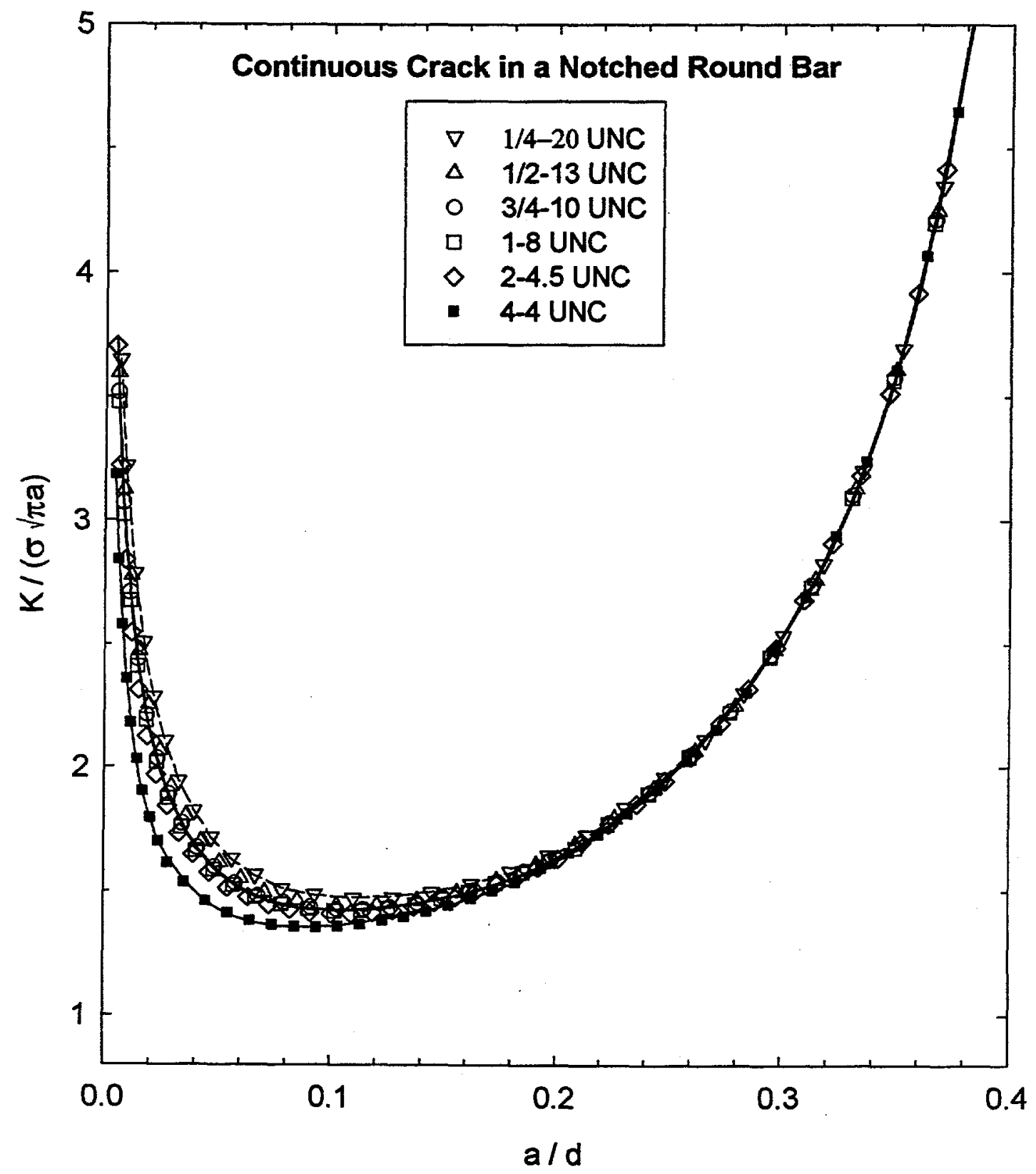

Figure 5 - Nondimensional $\mathrm{K}$ solutions for a continuous circumferential crack in a notched round bar. Notch geometries are consistent with UNC thread forms. Correlation equations for $\mathrm{K} / \sigma \sqrt{ } \pi \mathrm{a}$ as a function of $\mathrm{a} / \mathrm{d}$, as represented by the three lines, are provided in Table 2. 


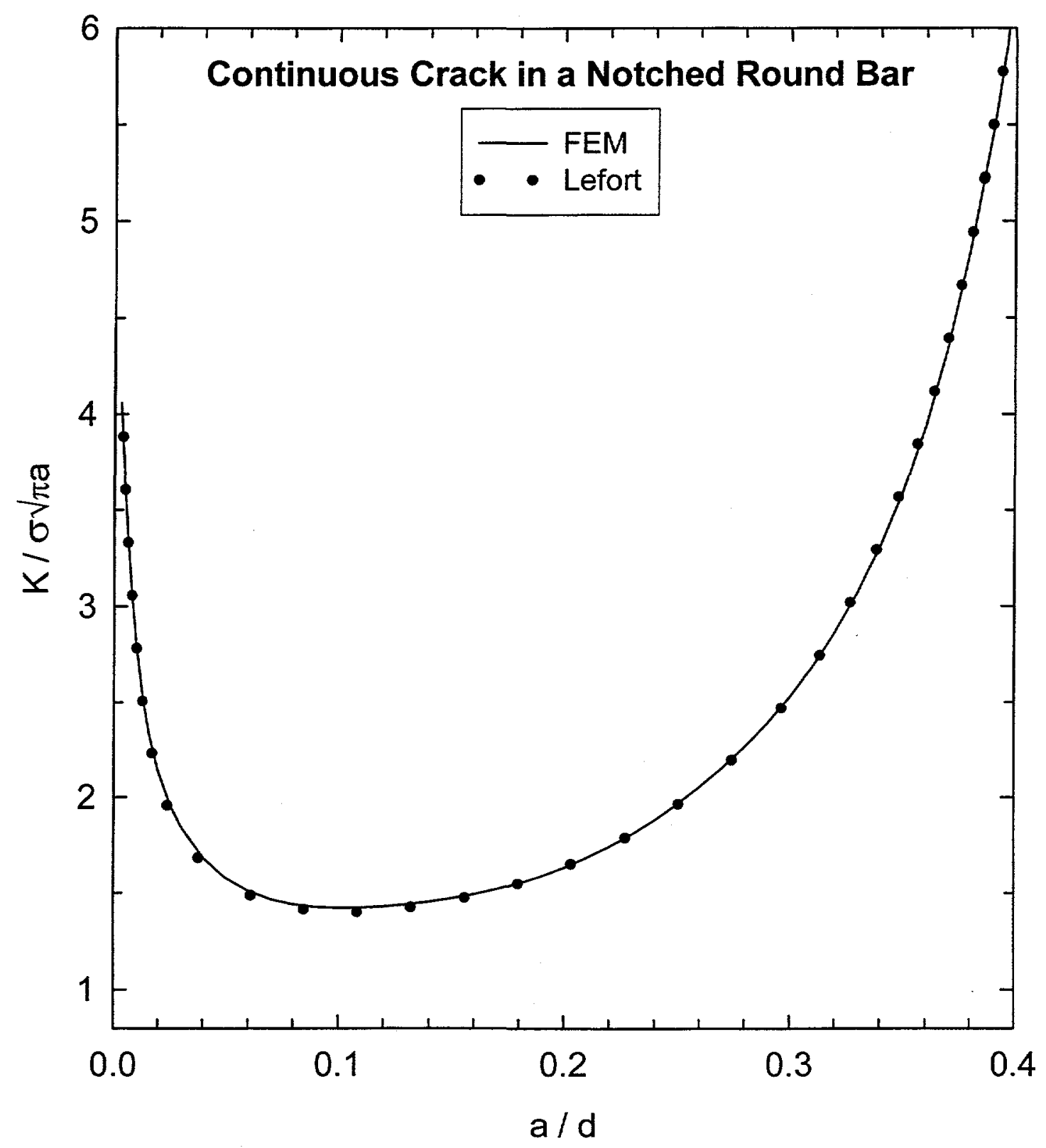

Figure 6- Nondimensional $\mathrm{K}$ solutions for a continuous crack in a round bar containing a single notch with a 1-8 UNC design. FEM solution, per Equation 3, agrees very well with Lefort solution. ${ }^{(8)}$ 


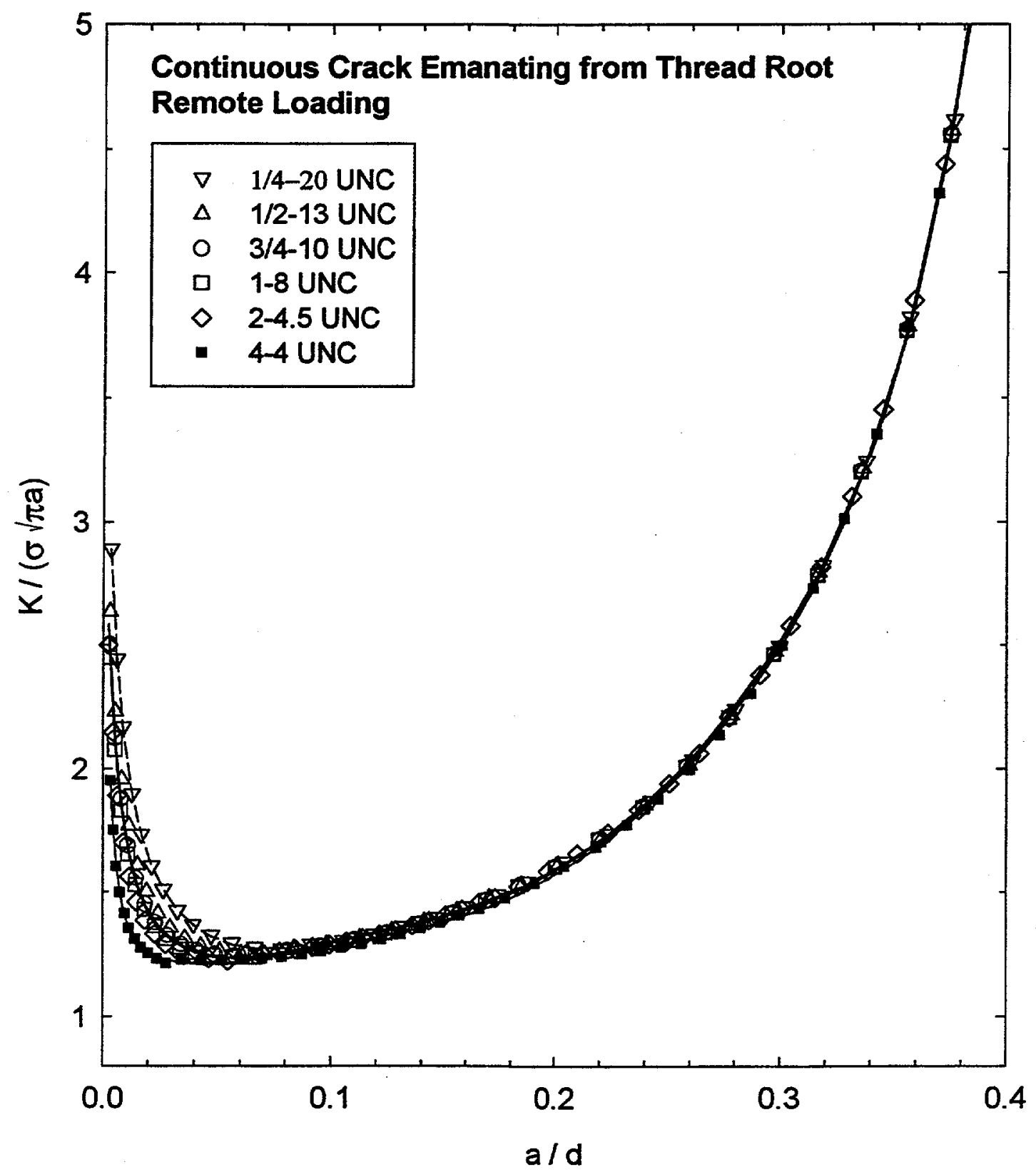

Figure 7 - Nondimensional $\mathrm{K}$ solutions for a continuous circumferential crack in a threaded fastener subjected to remote loading. Correlation equations for $\mathrm{K} / \sigma \sqrt{ } \pi \mathrm{a}$ as a function of $a / d$, as represented by the three lines, are provided in Table 2. 


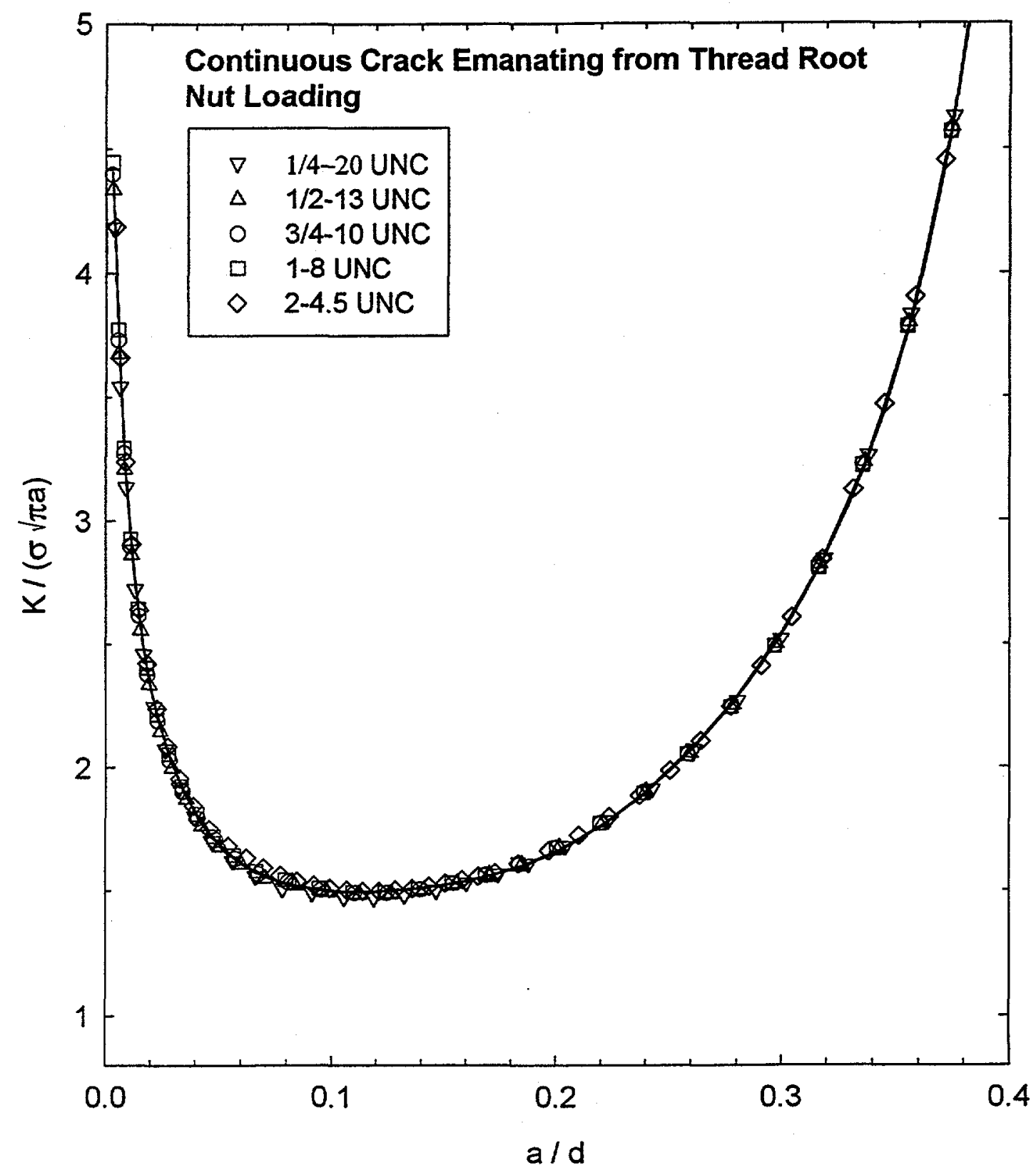

Figure 8 - Nondimensional $\mathrm{K}$ solutions for a continuous circumferential crack in a threaded fastener subjected to nut loading. The correlation equation for $\mathrm{K} / \sigma \sqrt{ } \pi \mathrm{a}$ as a function of $a / d$, as represented by the line, is provided in Table 2. 


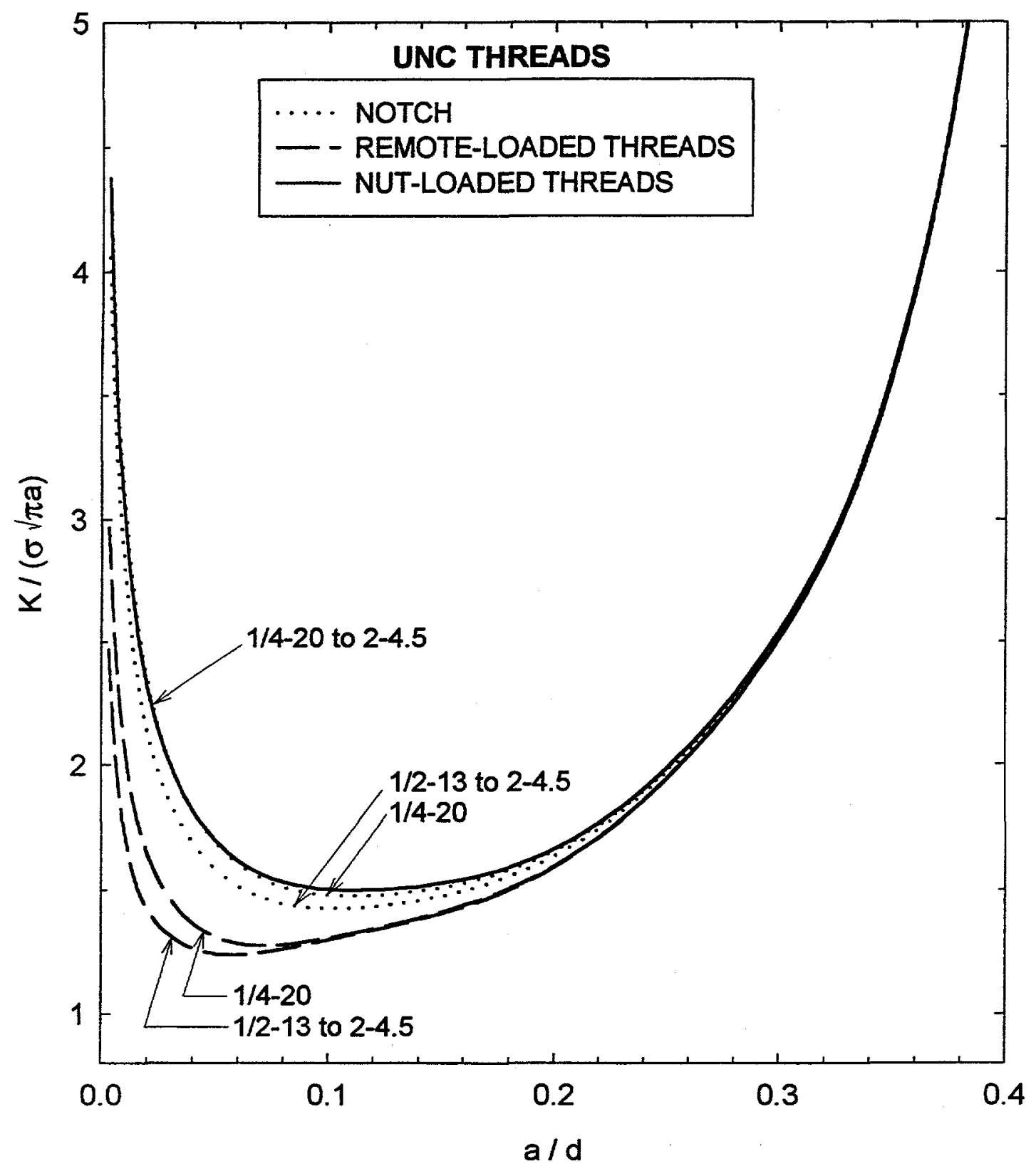

Figure 9 - Comparison of nondimensional $\mathrm{K}$ solutions for a notched round bar under remote tension and threaded fasteners under remote tension and nut loading. Regression constants for each curve are provided in Table 2. 


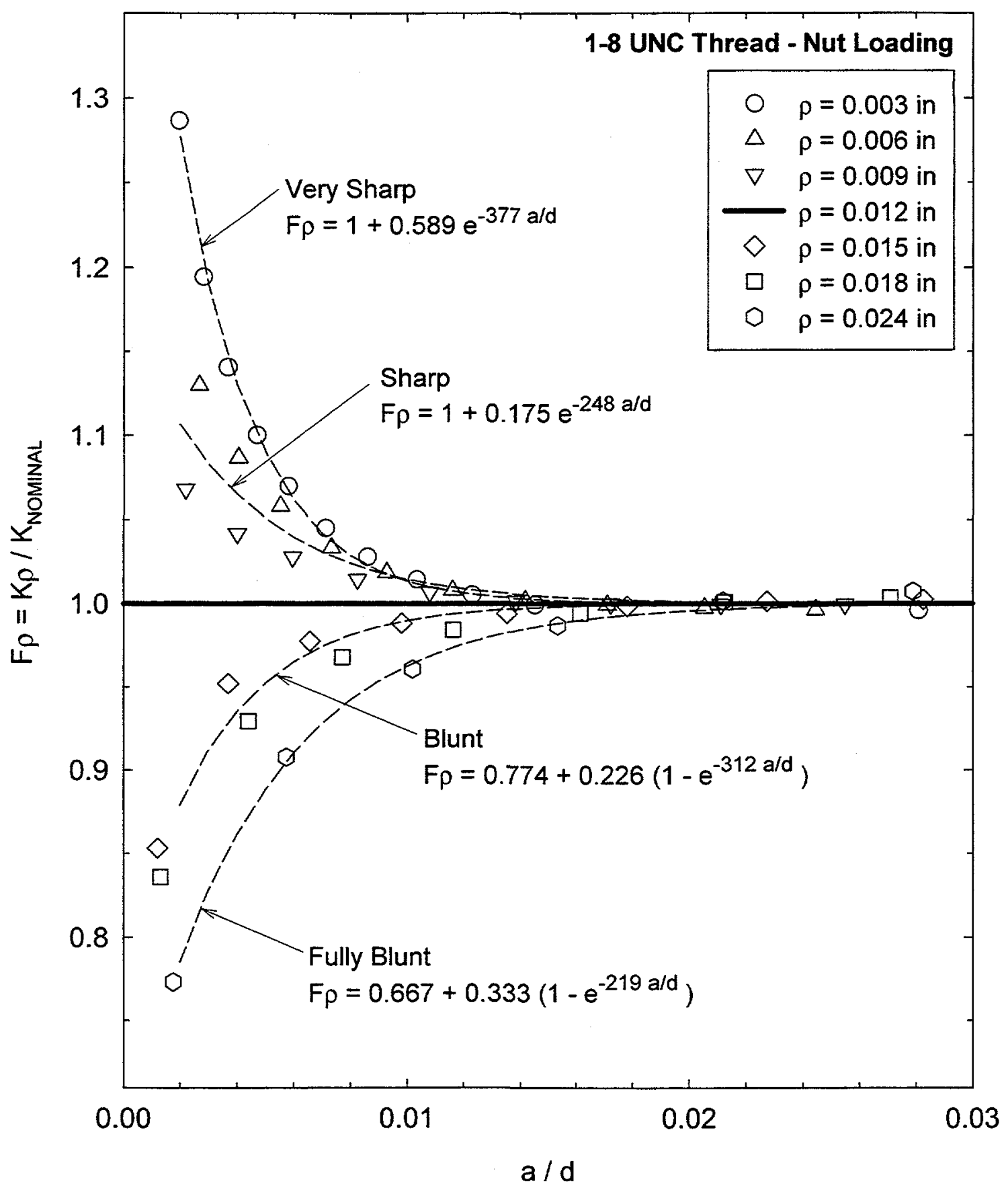

Figure 10 - Root radius correction factors for a 1-8 UNC threaded fastener subjected to nut loading. 


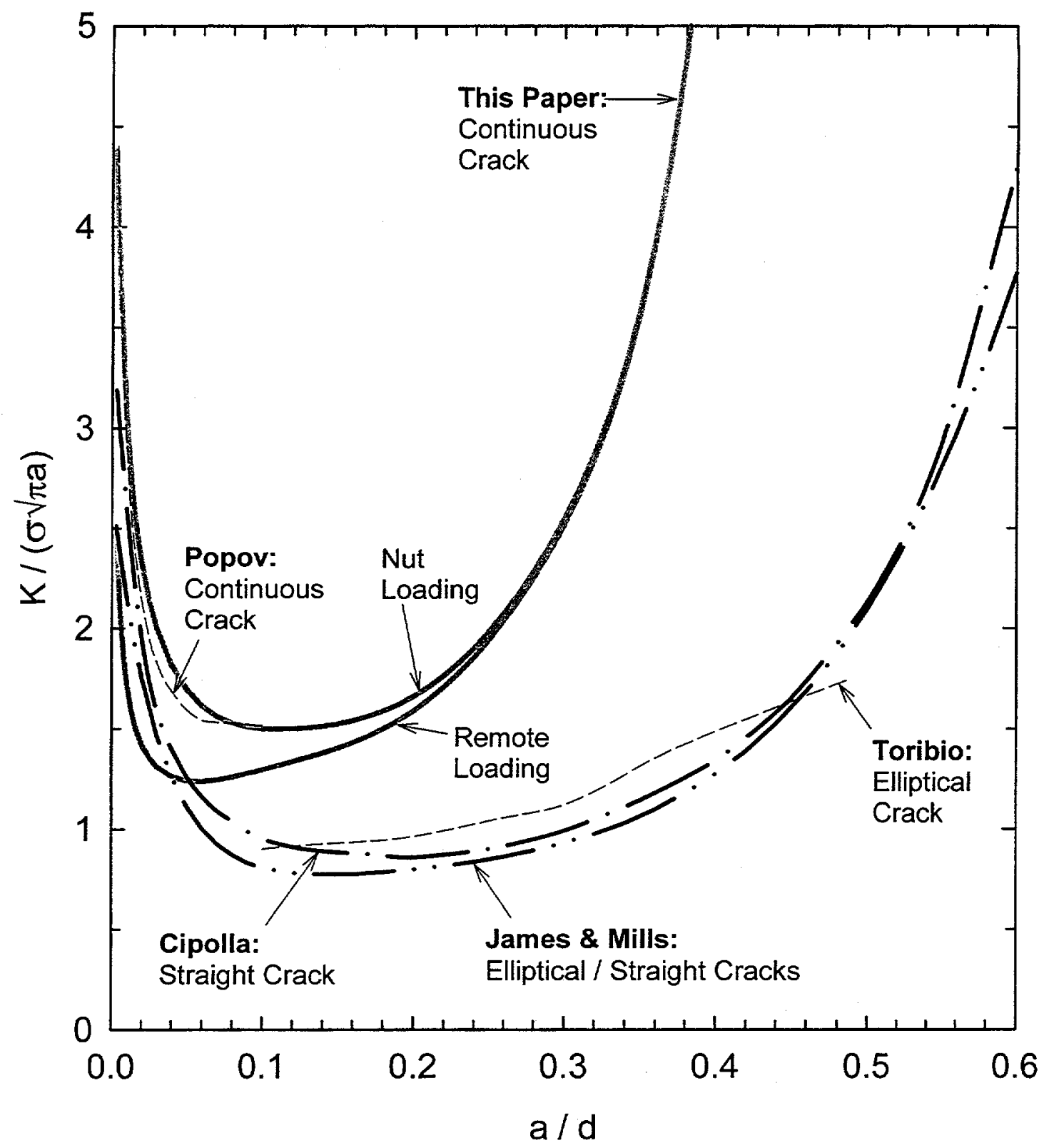

Figure 11 - Comparison of nondimensional $\mathrm{K}$ solutions developed by FEM analysis for fasteners subjected to nut loading and remote loading (solid curves) with literature solutions (broken curves)..$^{(1-3,6,7)}$ 